\title{
Controvérsias sócio-científicas e relações de poder: desafios de sua inserção segundo futuros professores de ciências.
}

DOI 10.26512/Ic.v24i0.21585

Graciella Watanabe
UFABC/Centro de Ciências Naturais e Humanas, graciella.watanabe@ufabc.edu.br

Pedro Guilherme Rocha dos Reis

Universidade de Lisboa/Instituto de Educação, preis@ie.ulisboa.pt

\section{Resumo}

A pesquisa em educação em ciências expôs a dificuldade na implementação de controvérsias sócio-científicas em sala de aula, particularmente em relação à infraestrutura e à formação de professores para lidar com atividades que vão além dos conceitos científicos. Vários fatores desestimulam os professores atuais e futuros a trabalharem na educação básica (fundamental e secundária) quando enfrentam o desafio de incluir tópicos não consensuais em suas aulas de ciências. Tendo em conta a situação política brasileira, esta pesquisa ilustra como os futuros professores compreendem suas ações e desafios, ao implementar controvérsias sócio-científicas. No contexto, apresentamos uma fração do trabalho desenvolvido no projeto "We Act", no qual pretendíamos pesquisar as percepções das relações de poder através das interpretações de Pierre Bourdieu e Paulo Freire. As concepções dos participantes sobre as relações de poder nas escolas, e como práticas políticas, surgem como particularmente relevantes para o que chamamos de "vigilância da profissão docente". Consequentemente, devese reconhecer que o contexto escolar é construído por influências sociais maiores do que a escola e a comunidade a que pertence.

Palavras-chave: Controvérsias sócio-científicas. Relações de poder. Formação de Professores. Pierre Bourdieu. Paulo Freire. 


\section{Abstract}

Science education research has exposed the difficulty in implementing socio-scientific controversies in the classroom, particularly regarding the infrastructure and teacher training to deal with activities that go beyond scientific concepts. Several factors discourage current and future teachers working in basic education (elementary and secondary), when facing the challenge of including non-consensual topics in their science classes. Taking into account the Brazilian political situation, this research illustrates how future teachers understand their actions and challenges, when implementing socio-scientific controversies. In the context, we present a fraction of the work developed in the "We Act" Project, where we intended to research power relations perceptions throughout Pierre Bourdieu and Paulo Freire interpretations. The participants' conceptions about power relations in schools, and as political practices, emerge as particularly relevant for what we call "supervision of the teaching profession". Consequently, it should be recognized that the school context is constructed by social influences greater than the school and the community it belongs to.

Keywords: Socio-scientific Controversies. Power Relations. Teacher Education. Pierre Bourdieu. Paulo Freire.

\section{Resumen}

La investigación en ciencias de la educación ha puesto de manifiesto la dificultad de implementar controversias socio-científicas en el aula, especialmente en lo que respecta a la infraestructura y la formación de docentes para abordar actividades que van más allá de los conceptos científicos. Varios factores desalientan a los maestros actuales y futuros que trabajan en la educación básica (primaria y secundaria), cuando enfrentan el desafío de incluir temas no consensuales en sus clases de ciencias. Teniendo en cuenta la situación política brasileña, esta investigación ilustra cómo los futuros docentes entienden sus acciones y desafíos, al implementar controversias socio-científicas. En el contexto, presentamos una fracción del trabajo desarrollado en el proyecto "Actuamos", donde intentamos investigar las percepciones de las relaciones de poder en las interpretaciones de Pierre Bourdieu y Paulo Freire. Las concepciones de los participantes sobre las relaciones de poder en las escuelas, y como prácticas políticas, emergen como particularmente relevantes para lo que llamamos "supervisión de la profesión docente". En consecuencia, se debe reconocer que el contexto escolar se construye por influencias sociales mayores que la escuela y la comunidad a la que pertenece.

Palabras clave: Controversias socio-científicas. Relaciones de poder. Formación docente Pierre Bourdieu. Paulo Freire. 


\section{Résumé}

La recherche en éducation scientifique a mis en évidence la difficulté de mettre en cuvre des controverses socio-scientifiques en classe, en particulier en ce qui concerne l'infrastructure et la formation des enseignants pour faire face à des activités qui vont au-delà des concepts scientifiques. Plusieurs facteurs découragent les enseignants actuels et futurs qui travaillent dans l'éducation de base (élémentaire et secondaire), lorsqu'ils doivent relever le défi d'inclure des sujets non consensuels dans leurs cours de sciences. Tenant compte de la situation politique brésilienne, cette recherche illustre comment les futurs enseignants comprennent leurs actions et leurs défis lors de la mise en œuvre de controverses socio-scientifiques. Dans ce contexte, nous présentons une partie du travail développé dans le projet "We Act», dans lequel nous avions l'intention de rechercher les perceptions des relations de pouvoir à travers les interprétations de Pierre Bourdieu et de Paulo Freire. Les conceptions des participants sur les relations de pouvoir à l'école et en tant que pratiques politiques émergent comme particulièrement pertinentes pour ce que nous appelons "la supervision de la profession enseignante». Par conséquent, il faut reconnaître que le contexte scolaire est construit par des influences sociales plus grandes que l'école et la communauté à laquelle il appartient.

Mots-clés: Controverses socio-scientifiques. Relations de pouvoir. Formation des enseignants. Pierre Bourdieu. Paulo Freire.

\section{Introdução}

As pesquisas em ensino de ciências que abordam controvérsias sócio-científicas tem demonstrado que a tentativa de inserir discussões que não sejam centradas unicamente no conhecimento científico ou na organização curricular pode gerar resultados importantes para a autonomia dos estudantes e na aprendizagem das ciências (Carvalho, \& Carvalho, 2012). Isso, pois ampliar o debate sobre o papel da ciência na sociedade e os riscos associados à inserção dos produtos desses conhecimentos no cotidiano possibilita que aspectos culturais sejam tratados nas salas de aulas. O objetivo para tal educação se coloca no reconhecimento, por parte dos alunos, de que os conhecimentos científicos são elementos de seu entorno social e, ao mesmo tempo, possibilita o entendimento dos riscos e benefícios desse saber na esfera da comunidade local e global (Engströn, \& Carlhed, 2014).

Mas, para o engajamento crítico e ativo nos problema sociais é importante que a ciência seja demonstrada em suas diferentes facetas. Por tal motivo, é relevante reconhecer, ao trabalhar com a ciência em contextos escolares, a dicotomia entre o contexto social 
e científico que interfere no entendimento e funcionalidade desse saber. E colocando, nesse conjunto de reflexões, ideias conceituais, políticas, econômicas e culturais que podem intervir nas relações entre sociedade e conhecimento científico. Há, por exemplo, dentro da sociologia da ciência estudos que apontam o papel da ciência como promotora da desigualdade social. Para Tilly (2006), quando existe um fosso entre aqueles que sabem e os que não sabem sobre conhecimentos científico-tecnológicos o que se está definindo é uma estrutura social baseada em aquisições simbólicas (e, também, materiais) entre incluídos e excluídos da participação em decisões relevantes para a sociedade.

Bencze e Carter (2011) participam desse debate incluindo a educação como parte desse processo neoliberal de sociedade, cujo um dos objetivos é a tentativa de limitar o processo de aprendizagem ao reconhecimento de fórmulas e teorias. Reis (2014a) acrescenta que para superar tal educação é necessário compreender as tensões individuais e coletivas que permeiam temáticas científicas inserindo controvérsias como capazes de potencializar a reflexão e tomada de consciência dos alunos.

Em outras palavras, trazer para o contexto da sala de aula questões que permeiam as ciências, os problemas sociais que elas podem acarretar e as tensões geradas pelo conflito de interesses são a tentativa de iniciar um processo que possa superar a ideia de que existe uma correlação direta entre ciência e legitimidade. Desmistificar e reconhecer as intencionalidades individuais e coletivas dos discursos (Reis, 2014a) é promover a conscientização de que a formação escolar é, também, parte de um compromisso e ideal de sociedade democrática. Por tal motivo, percebe-se que 0 descompasso entre os conhecimentos escolares e o que é produzido na sociedade já não parece ser o fator mais determinante para o tipo de educação que se presencia, mas sim as dificuldades de professores em convergir para um discurso comum. Diante das constantes intervenções políticas que a escola deve administrar atualmente, percebe-se que as negociações da esfera escolar com outros espaços sociais acabam desviando as lutas e sentidos para outros campos, levando ao esquecimento do debate sobre os objetivos educacionais que se pretende ao formar o aluno que se defende nesse trabalho, ou seja, para a participação em uma sociedade democrática.

Esse tipo de artimanha social leva ao entendimento de que a ciência, nesse contexto, mesmo que já não se tenha a credulidade total de sua neutralidade, acabe por ser mascarada como conhecimento infalível. Isso, pois como lembram Bencze e Carter (2011) e Bourdieu e Passeron (1965) a escola acaba por se constituir como máquina de produção de crenças e onde pode contribuir para a alienação em detrimento da urgência da aquisição do saber específico de modo contextual. Por outro lado, essa mesma escola é capaz de promover mudanças, visto que em muitos lugares é o único bem cultural que chega às comunidades. Paulo Freire (1975a) era um dos intelectuais que acreditava no papel da educação como estimuladora da reflexão e da tomada de consciência dos que para ele estavam em situações de opressão. 
Sendo a escola esse espaço de dupla atuação, o discurso da ciência pode ganhar duas vertentes distintas: da alienação ou da reflexão crítica. Um caminho possível para seguir a segunda perspectiva está no reconhecimento provindo dos trabalhos de Tilly (2006) e Levinson (2006) quando esses apontam sobre como o conhecimento pode se tornar instrumento potente da desigualdade social e, de certo modo, como aprender sobre controvérsias sócio-científicas perpassa questionar aspectos éticos, de reconhecimento das responsabilidades e do exercício da empatia. Concebendo uma educação em que se reconheça que não se tem um ponto de vista, mas distintas respostas e solução dadas por distintos grupos (Levinson, 2006).

É importante lembrar, no entanto, que quando se defende a necessidade da reflexão sobre os problemas sociais e questões éticas e morais não se pretende conduzir ao esvaziamento dos conhecimentos científicos no contexto escolar (Levinson, 2006). Essas ações fazem parte de uma preocupação mais abrangente que se refere a atividades que possam ser inseridas em salas de aulas de ciências e que tragam, de certo modo, aprendizagens que sejam importantes social e culturalmente para os alunos. Segundo Pozo e Crespo (2009) o desafio em ensinar não está na mera aprovação baseada em critérios avaliativos utilizados pelos docentes, mas na superação do ensino científico que não se esvaeça rapidamente. Para esses autores, resolver problemas de modo repetitivo gera uma percepção equivocada sobre o "exercício reflexivo da ciência ao invés de encará-los como tarefas que exigem reflexão e tomada de decisões" (Pozo \& Crespo, 2009, p. 17).

Contextualizado por esses debates, a formação do professor torna-se fator determinante para o desenvolvimento das ações e inserções de temas não consensuais nas escolas e na perspectiva da educação crítica. É evidente que tal formação não é trivial, requer um conjunto de habilidades que não podem ser exclusivamente desencadeadas em curtos períodos de tempo e requer uma estrutura colaborativa razoavelmente extensa para efetivar a inserção das controvérsias sócio-científicas nas salas de aulas. Para Reis (2014a, 2014b) há um desenho de processo interventivo que pode auxiliar os professores no planejamento de aulas de ciências baseadas em questões sócio-científicas:

1. Pela promoção de aprendizagens ativas baseadas em investigações sobre as controvérsias da vida real;

2. Pelo estímulo da participação dos estudantes na ação coletiva e democrática de resolução de problemas.

Nesse tipo de perspectiva educacional as atividades de ensino são constituídas de ações voltadas a discussões e ao uso do discurso de modo que o mesmo seja embasado por conhecimentos científicos que, por sua vez, constituem-se na construção de 
articulações que perpassam a história, filosofia e sociologia da ciência, configurando-se essas aprendizagens como partes importantes da aquisição de atitudes para o ativismo democrático (Linhares \& Reis, 2014).

Ainda que essas propostas sejam coerentes e baseadas em pesquisas educacionais, pouco se tem observado da inserção desses temas nos contextos das aulas ou, em especial, na proposição de currículos que priorizem as abordagens sócio-científicas. Dentre a diversidade de fatores já relatados pela literatura (Reis, 2014a) situações de relações de poder que ocorrem no espaço escolar parecem ter lugar privilegiado nesses impasses. Assim, o que se pretende nesse artigo é investigar:

De que tipos e de qual esfera social estão sendo percebidas as relações de poder que influenciam a tomada de decisão de futuros professores para a inserção (ou não) de controvérsias sóciocientíficas em suas salas de aulas de ciências?

No contexto da formação de futuros professores, apresenta-se parcela do trabalho desenvolvido no contexto do projeto "We Act"1 (Reis, 2014b) onde se pretende investigar as percepções de relações de poder através da interpretação de Pierre Bourdieu e Paulo Freire. Nas seções seguintes argumenta-se a favor do diálogo e limites da aproximação desses dois autores e suas potencialidades para a interpretação dos discursos analisados.

\section{Referencial teórico}

Michael Burawoy em seu livro "O marxismo encontra Bourdieu" (2010) procurou promover um diálogo imaginado entre Pierre Bourdieu e alguns marxistas. Beauvoir, Gramsci, Marx e Fanon são alguns desses intelectuais que "dialogaram" com o discurso bourdieusiano. Na versão brasileira do livro o autor apontava certo descontentamento por ter deixado de fora o interlocutor Paulo Freire. Reconhecia que ambos tinham um olhar para a educação que não poderia ser ignorado e que, em certos termos, tinham aproximações no sentido em que compreendiam o papel da educação como transformadora do mundo.

Do ponto de vista do trabalho intelectual, cada autor compreendia diferentemente seu papel. Enquanto Bourdieu acreditava que o trabalho do sociólogo tinha o objetivo de desvelar o mundo, as relações de dominação, mas, sem intervir na realidade estudada, Freire acreditava em um intelectual atuante, imerso nos problemas estudados e evidenciados pela pesquisa intelectual. Havia na perspectiva freireana uma interação

1 We Act (Nós Agimos) é um projeto que busca trabalhar com diferentes atores sociais para promover a inserção de atividades baseadas nas controvérsias sócio-científicas em contextos educacionais. 
forte entre trabalho e atividade intelectual e que ambas não eram separadas da cultura (Vittoria, 2011). Transformar a realidade e consequentemente a cultura era um papel importante do professor, do pesquisador e do mundo pesquisado. Isso significa que cada um de nós é sujeito de um processo transformacional, é criador e recriador da realidade (Freire, 2013a).

Bourdieu, por sua vez, primava pelo reconhecimento da sociologia como pesquisa empírica e racional, sendo, portanto, fortemente influenciado pela filosofia de Gaston Bachelard e, por isso, também, reconhecido como um racionalista aplicado. Ainda que ele tenha participado ativamente de movimentos sociais e se aproximado dos dominados, promovendo palestras e discussões em diferentes espaços educacionais e sociais, e compreendo tais trabalhos como parte do desvelamento do jogo social.

O que nos parece ser um ponto de aproximação entre esses dois autores está na preocupação de ambos com esse termo: relações de poder. No livro Senso Prático (1980) Bourdieu explora de modo bastante detalhado a importância dessas relações em seus estudos epistemológicos e sociológicos. $\mathrm{O}$ autor defende que a interpretação das relações entre pessoas instituídas pelas práticas sociais corriqueiras é, em suma, baseada em relações de poder onde cada um dos agentes possui uma posição bem definida nesse processo. Assim, era sempre necessário questionar qual a posição do sujeito na estrutura social e só assim poder caracterizar a função desse agente na interação estabelecida entre quem doa e quem recebe.

Essa dimensão é importante, pois aponta que o conceito operante na teoria de Bourdieu é o de luta (Wacquant, 2005; Catani, 2013) e não reprodução, como se tem discutido por diferentes autores em educação. Esse processo de compreensão das relações de poder aponta para a importância de questionar se o discurso de um agente é mais crível de respeitabilidade do que de uma pessoa que estuda o tema, mas que pode não possuir uma posição importante no campo. O que a relação de poder impõe é um tipo de compreensão do mundo social em que o campo norteia discursos a partir de suas posições na estrutura social. Ou seja, o que tomamos como valorizado como discurso por um agente, pode ser totalmente ignorado se for falado por outro.

O caso da ciência é interessante, pois ter acesso a ela dá ao seu possuidor um poder relativamente importante nos discursos sobre controvérsias sócio-científicas. Isso, pois o detentor desse saber, o cientista, é uma pessoa que pode transitar entre diferentes campos, gozar de reconhecimento no campo científico, e ainda, ser um agente reconhecido em outros campos sociais. Sua capacidade de influência gera interlocuções com agentes sociais distintos e, consequentemente, aumenta as redes de proteção e legitimação da ciência.

Se as questões sócio-científicas são formas de introduzir na escola reflexões e ações que comprometam a legitimidade cega da ciência, é importante pensar que baseados nos trabalhos de Bourdieu, utilizar tais temáticas em sala de aula é modificar as relações de poder já estabelecidas na sociedade. Implica, portanto, descaracterizar 
um conjunto de artimanhas que se conglomeram para construir uma complexidade de conhecimentos e, por vezes, fruto dos lucros (sociais, econômicos, políticos) obtidos em diferentes instâncias e campos sociais.

A argumentação de que essa escola comprometida com questões sócio-científicas seja capaz de superar vínculos morais e sociais recai na crítica de Freire do perfil da escola que possui o interesse em formar uma elite e excluir o restante da sociedade, tornando-a mão de obra barata (Freire, 2005; Freire, 2013b). Esse dualismo entre intelecto e trabalho, rico e pobre, elite e proletariado a que se refere Freire e que foi muito utilizada por Pierre Bourdieu, é uma visão criticada pelos autores e nada mais é do que um modelo herdado pela educação colonizadora como no caso brasileiro (Freire, 2013a).

Foi para superar essa dicotomia que Freire se debruça, também, no entendimento mais profundo do sentido de relação, pensando-a como parte de um problema maior, histórico e cultural. Assim, a educação para a liberdade seria um modo de desconstruir relações marcadas por laços de poder, onde opressor reconhece-se como benfeitor do oprimido, sem perceber, contudo, que ambos estão presos da armadilha social das relações de poder (Freire, 2005).

Nesse sentido, pode-se reconhecer que o objetivo do reconhecimento do saber científico como dual e controverso constitui parte de um processo de superação da cultura do silêncio. É, de certo modo, alfabetizar, "letrar", dar voz ao oprimido, possibilitando o reconhecimento da sua situação nesse processo:

A opressão cria um silêncio que pronuncia palavras de dominação, resignação. A cultura do silêncio não pode ser compreendida se não for analisada como parte de um sistema maior e mais complexo, procurando as condições que a provocam (Freire, 2013a). Isso significa que ela não surge espontaneamente e não se autogera, mas se forma nas relações. Portanto, para compreendê-la, é necessário analisar o fenômeno da dependência relacional, no qual os dominados assimilam os mitos culturais dos dominadores, criando uma ambivalência, uma ambiguidade, um sentimento de repulsa e atração pelo opressor e, consequentemente, a negação da palavra, da linguagem, do pensamento autônomo (Vittoria, 2011, p. 118).

Para Bourdieu e Freire a relação é um instrumento, um meio para compreender, superar e desmistificar. O trabalho de reinventar as relações de modo reflexivo é a condição primeira para a mudança de comportamento, o reconhecimento da ação política como transformadora do mundo e o empowerment para a participação democrática.

Existem dois efeitos para o entendimento de que compreender o sentido das relações, as posições de poder entre os agentes envolvidos na relação e a reflexão do oprimido/ dominado como agente desse processo relacional pode gerar para a educação. $O$ primeiro é freireano e constitui como prática fundamental da democracia, ou seja, o reconhecimento de que as relações são construídas e não dadas, leva a exigência na 
luta e na necessária reflexão pela transformação do mundo (Freire, 2013b). O outro efeito recai na superação do que Bourdieu chama das "ideias feitas". Significa não permitir ao opressor/dominador elaborar a "reflexão" pela legitimação social que ele goza no campo de poder:

As "ideias feitas" de que fala Flaubert são ideias aceitas por todo mundo, banais, convencionais, comuns; mas são também ideias que, quando as aceitamos, já estão aceitas, de sorte que o problema da recepção não se coloca (Bourdieu, 1996, p. 40).

Ainda que as ideias científicas não sejam banais/comuns/convencionais, é importante retomar a condição de elaboração, constituição e caracterização de um modo de pensar que não é estático quando se refere ao conhecimento científico. Contudo, deve ser questionado, criticado e, talvez, deslegitimado no debate democrático quando contrapuser ideais e decisões sociais baseadas na construção de um projeto político de participação cidadã.

Desse modo, com o objetivo de apresentar subsídios ao entendimento dos conceitos tratados nesse trabalho, aponta-se a relevância desses autores para o reconhecimento de que as lutas dentro do espaço escolar se dão em diferentes esferas sociais, o que constitui parte de um aparato mais amplo de embates de perspectivas educacionais que hoje estão em jogo no Brasil. No caso da inserção de atividades de cunho crítico, como são marcadamente as controvérsias sócio-científicas, diferentes grupos sociais entram em conflito pela demarcação de seus espaços de interesse, dando (ou não) suporte aos professores as utilizarem em suas salas de aulas.

Nas próximas seções, apresentar-se-á a investigação em que se procurou compreender os empecilhos relacionados à inserção das controvérsias sócio-científicas pelos professores e compreender de que modo as relações de poder estão sendo percebidas como parte desse desafio tratado nos discursos dos pesquisados.

\section{Metodologia de Pesquisa}

A pesquisa-ação é um termo utilizado por pesquisadores para reconhecer projetos práticos que buscam transformar a prática dos agentes que participam da pesquisa (pesquisados e pesquisadores). Pode ser definida como uma forma de investigação-ação que utiliza técnicas de pesquisa consagradas para informar a ação que se decide tomar para melhorar o ato investigativo (Tripp, 2005, p. 447). Ainda que tenha uma perspectiva prática bastante salientada, esse tipo de investigação tende a ser pragmática, capaz de alterar o que é pesquisado e, ao mesmo tempo, se preocupar com a ética no contexto da pesquisa (Tripp, 2005). 
Nesse trabalho, reconhece-se a pesquisa-ação como modalidade socialmente crítica, onde se trabalha para mudar e contornar limitações da realidade escolar vivenciada pelos professores. Em suma, é a procura por mudanças como:

"(...) o aumento da igualdade e oportunidade, melhor atendimento às necessidades das pessoas, tolerância e compreensão para com os outros, cooperação maior e mais eficiente, maior valorização das pessoas (de si mesmo e dos outros) e assim por diante. Essas são as "grandes ideias" de uma sociedade democrática" (Tripp, 2005, p. 458)

Para Franco (2005), por tais características da pesquisa-ação e seus princípios geradores pode-se a compreender como uma pesquisa eminentemente pedagógica, dentro da perspectiva de ser o exercício pedagógico, configurando como ação que "cientificiza" a prática educativa (Franco, 2005, p. 489) de modo a promover a formação de todos os sujeitos da prática. Para essa autora, a pesquisa-ação pode ser um importante instrumento de formação do professor, construindo modos de atuação que possam correlacionar com a reflexão da situação vivenciada (Franco, 2012).

Salienta-se que a escolha pelo viés epistêmico que prioriza a intervenção social e a construção de ações e parcerias consideradas significativas pelos pesquisados se tornou determinante pela escola crítico-emancipatória como instrumento de reconhecimento e desvelamento do mundo social pesquisado:

Nessa perspectiva, espera-se que a realização da pesquisa-ação se constitua em um processo por meio do qual os participantes possam desenvolver um estilo de questionamento crítico sobre suas práticas, visando transformá-las (Franco \& Lisita, 2012, p. 52).

No que tange as etapas da pesquisa, apesar de não seguir uma linearidade, devem estar presentes no processo de construção do problema: construção da dinâmica coletiva, ressignificação das espirais cíclicas, produção e socialização do conhecimento, avaliação das práticas e conscientização das novas dinâmicas (Franco, 2012).

Para Barbier (2002) a abordagem espiral é um dos pilares da pesquisa-ação. Essa dimensão recursiva de reflexão permanente que está associada a investigação espiral tem a função de promover instrumentos de reflexão e avaliação do processo, formação coletiva e capacidade de compreender as diferentes partes da tríade pesquisa/ação/ reflexão (Franco, 2012). Nesse processo o pesquisador e pesquisa possuem espaços para reflexão e compartilhamento das práticas sociais através da escuta e divisão das experiências vividas. Alguns autores desenham tal prática a partir de exercícios contínuos, ou seja, etapas das espirais cíclicas: planejamento ? ação ? reflexão ? pesquisa? ressignificação? replanejamento.

O planejamento para o desenvolvimento da pesquisa foi elaborado concomitantemente aos estudos dos textos e ao debate com os pares. A partir da organização conceitual do trabalho, propôs-se a elaboração de um plano de apresentação, discussão e coleta 
de dados. A etapa inicial refere-se a elaboração de ações-práticas em um curso de Licenciatura em Pedagogia e o debate sobre a inserção de controvérsias sóciocientíficas em aulas de ciências dos anos iniciais da escolarização com três turmas de estudantes do $3^{\circ}$ semestre do curso em uma disciplina de Ensino de Ciências e Tecnologia de uma universidade pública brasileira.

Foram feitas três intervenções específicas para o grupo de pedagogos na disciplina em que foram apresentados os temas de epistemologia e sociologia da ciência, metodologia do ensino de ciências, temáticas atuais das pesquisas em ensino de ciências e atividades experimentais. As aulas eram distribuídas em dois dias da semana com carga horária de 2 horas/aula para as duas turmas do diurno e 4 horas/aula, uma vez por semana, para a turma do noturno.

No penúltimo mês da disciplina - maio de 2016 -, dedicado aos estudos de temáticas atuais, foi inserido um bloco de três aulas sobre as controvérsias sociocientíficas. Anteriormente, em outros blocos os alunos já haviam debatido sobre a sociologia da ciência, estereótipos dos cientistas e o papel da mídia, abordagem CTS, perspectiva freireana e atividades experimentais. Assim pretendia-se trazer um reconhecimento geral sobre os tópicos anteriores que pudessem subsidiar o entendimento acerca do tema aqui apresentado. Inicialmente, os alunos foram convidados a lerem o artigo ${ }^{2}$ sobre o tema, em seguida, desenvolveu-se com o grupo a organização do debate entre a turma. O texto foi escolhido pelo panorama geral que o autor apresenta sobre o tema, tratando não só as potencialidades como os problemas que as pesquisas atuais têm percebido na inserção dessas ações em sala de aula.

Foram analisadas três turmas, sendo uma do período matutino $(n=25)$, outra turma do período vespertino $(n=26)$ e a turma do noturno $(n=26)$. Finalmente, seguiu-se de um debate com os alunos (foram três gravações respectivamente para cada turma com cerca de 50 minutos de áudio) em que foram gravadas as falas dos estudantes. Nesse momento, a pesquisadora iniciou a discussão questionando a relevância, os desafios e as potencialidades que os alunos percebiam ao trabalharem com o tema nas aulas de ciências nos anos iniciais.

\section{Resultados e discussões}

Nesse capítulo, optou-se pela apresentação e análise dos dados de modo concomitante. Isso, pois se objetiva trazer as percepções, produções e debates como parte de um processo de interação entre investigados e pesquisador em que a tomada de

2 "Da discussão à ação sociopolítica sobre controvérsias sóciocientíficas: uma questão de cidadania" publicada em 2013 na revista Ensino de Ciências e Tecnologia do autor Pedro Reis 
consciência se constitui ao passo que se produz e se questiona durante o processo. A partir dessas concepções, foi utilizado como referencial de análise Laurence Bardin (2009). Para a organização do trabalho, inicialmente se propôs a leitura flutuante de modo a construir uma referenciação dos índices e posterior elaboração de indicadores. A partir desses indicadores foi elaborado a codificações e construção das categorias de análise (Bardin, 2009).

Para a análise dos resultados foi construída uma matriz de análise com a organização: tema, categoria, subcategoria, indicadores/unidades de registro e unidades do texto. No tema, se procurou perceber na fala dos investigados as preocupações mais amplas sobre as intervenções externas no contexto escolar. As categorias são responsáveis pela compreensão de como o tema pode ser fragmentado em outras possíveis relações de interesses como políticos, sociais ou culturais. As subcategorias buscaram trazer a dimensão dos interesses específicos dessas categorias. Finalmente, apresentam-se as unidades e indicadores que foram percebidos como representativos dos discursos dos sujeitos e consequente apresentação de unidades do texto (fala dos investigados) que são representativas da categoria estudada.

Todo o processo de análise é constituído de um olhar epistemológico em que se pretende observar o papel das relações de poder como instrumentos de imposição de determinadas ações e empecilhos dos agentes sociais no campo de atuação (Bourdieu, 2014). Desse modo, o reconhecimento do papel da escola como esse espaço de manutenção ou superação das desigualdades sociais pode ser um importante meio de construir e pensar sobre práticas que promovam a autonomia do pensamento do aluno e também do professor (Freire, 2013b). Baseadas nas controvérsias sócio-científicas pretende-se analisar como os futuros professores percebem as potencialidades, desafios e limitações em inserir essa perspectiva educacional em suas futuras aulas de ciências. A partir desse processo reflexivo, objetiva-se propor subsídios para a articulação entre essas diferentes preocupações (Figura 1).

Figura 1: O processo de análise para a construção de subsídios para o debate

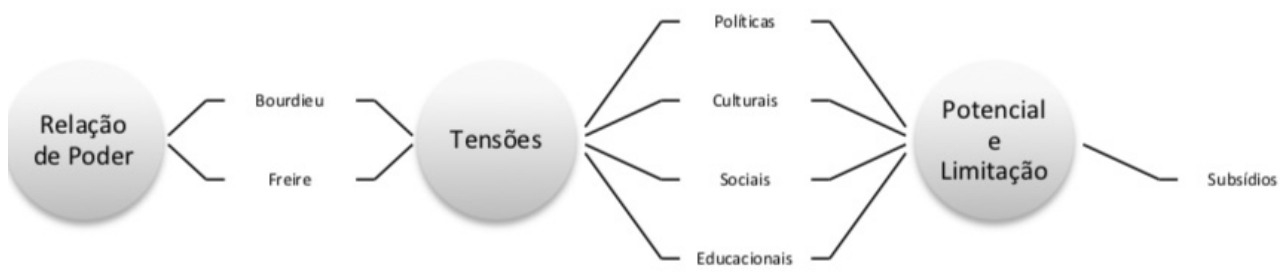


Através da análise dos discursos dos futuros professores apresentam-se dois temas emergentes sobre as controvérsias sócio-científicas: relações de poder na sociedade e superação dos problemas. Esses temas serão apresentados em matrizes de análise com o objetivo de exemplificar algumas falas representativas das categorias acima citadas.

Assim, no que tange o primeiro tema "Relações de Poder na Sociedade", conforme os alunos apontaram suas percepções sobre as dificuldades que poderiam influenciar a inserção das controvérsias sócio-científicas em suas futuras aulas de ciências, aspectos culturais foram apontados como um desses fatores (Tabela 1). Contudo, no âmbito da cultura a questão moral é um dos temas que aparece como aspectos a tratar quando estão sendo abordadas questões sócio-científicas, são preocupações que apontam para o respeito pelas opiniões pessoais. Outro aspecto associada à cultura está no papel da família como parte da construção das relações do âmbito escolar. Famílias conservadoras, em geral, segundo os investigados, se posicionam de modo a dificultar o diálogo e consequente mobilização dos alunos diante de problemas que são considerados não consensuais da ciência segundo as crenças e valores dessas famílias. A religião também possui essa característica de abster o debate e não conduzir a novos entendimentos sobre o mundo cujas ideias entram em embate com o saber religioso.

No âmbito da escola aparecem dois possíveis empecilhos para a inserção das controvérsias sócio-científicas. O primeiro está associado à postura ou a mudança de postura do professor diante das incertezas relacionadas a esse tipo de abordagem. A autoridade do conhecimento científico acaba por ser um fator determinante para o controle da sala que, segundo os investigados, não parece ser um elemento de fácil mudança na prática docente, nesse caso, a relação de poder está na interação professor-aluno. O outro elemento é a estrutura da escola, a instituição pode ter o poder de gerir e controlar seus funcionários, seja através do currículo ou do perfil ideológico da instituição, sendo, para os futuros professores, um desafio que não pode ser ignorado. Segundo esses sujeitos, as relações democráticas devem ser iniciadas dentro da própria instituição, na prática e não somente na teoria.

O âmbito político, externo ao contexto escolar, influencia de modo significativo as relações internas, portanto, leis e projetos curriculares acabam por instituírem em políticas públicas que obstruem a mudança nas escolas. Nesse contexto, os investigados apontam que a conservação pela escola tradicional constitui um interesse do Estado que visa manter agentes sociais passivos e poucos críticos a questões que possam envolver temáticas científicas. Foi chamada atenção, também, para grupos políticos que assumem nos espaços de decisão no poder a defesa por visões ideológicas que mudam ou mantem percepções educacionais conforme seus interesses. Exemplos como a dita "bancada evangélica" que defende a retirada de temas como a "Evolução" ou a inserção da temática criacionista nos currículos de ciência.

Nesse primeiro tema, o que se percebe é que os futuros professores compreendem diferentes relações de poder que influenciam a sua atuação em sala de aula. 
Chama a atenção para a construção de um pensamento em que as relações não se focalizam apenas no microcosmo da sala de aula, mas como um lugar em que diferentes lutas estão sendo travadas para a tomada ou manutenção do poder (Bourdieu, 2014). A questão política não está esquecida, visto que os investigados apontam que trazer indagações que não se limitam ao aprendizado tradicional, sem reflexão ou contestação, mas que evocam a criticidade e a construção de processos de transformação do mundo (Freire, 2005) é um tipo de educação que pode ser contestada pelos interesses políticos e ideológicos que os acompanham.

Tabela 1: Matriz de análise das relações de poder:

\begin{tabular}{|c|c|c|c|c|}
\hline Tema & Categorias & Subcategorias & $\begin{array}{l}\text { Indicadores/ } \\
\text { Unidades de } \\
\text { Registro }\end{array}$ & Unidades do Texto \\
\hline $\begin{array}{l}\text { Relações } \\
\text { de poder na } \\
\text { sociedade }\end{array}$ & Âmbito cultural|. & Moral & $\begin{array}{l}\text { "questões morais" } \\
\text { "pessoais" } \\
\text { "internas" }\end{array}$ & $\begin{array}{l}\text { “Esses conhecimentos, } \\
\text { como eles envolvem } \\
\text { questões morais e } \\
\text { questões pessoais até, } \\
\text { não só sociais, mas } \\
\text { pessoais...” } \\
\text { "(...) essas questões por } \\
\text { que ele envolve não } \\
\text { se trata só da ciência } \\
\text { como algo isolado, } \\
\text { como algo externo, } \\
\text { ela envolve também } \\
\text { questões internas" } \\
\ldots \text { "Minha família é bem } \\
\text { conservadora e bem } \\
\text { tradicional” } \\
\text { "(...) eles jả se } \\
\text { posicionam de tal } \\
\text { forma que não vou } \\
\text { discutir com você } \\
\text { sobre o que você acha, } \\
\text { já impõe e querem } \\
\text { que você tenha esse } \\
\text { mesmo pensamento" }\end{array}$ \\
\hline
\end{tabular}




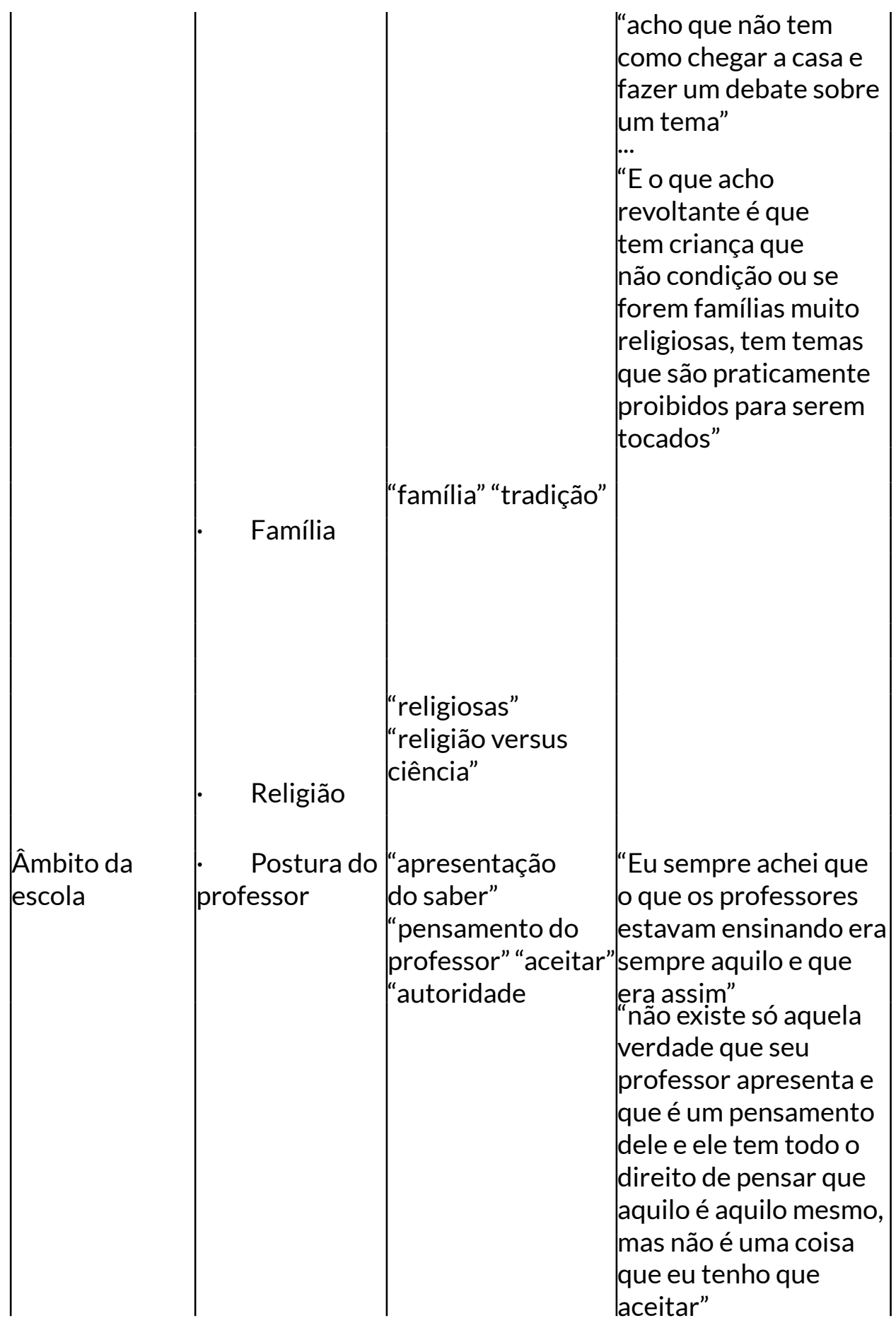




"são professores e tem
mais conhecimento
que você e então, se
você falar é você que
não estuda e não sabe.
'Eu sou professor, sou
autoridade"”
“. (...) estar inserido no
contexto social de
participar e discutir
e de estar envolvido,
para mim envolvem
primeiro a consciência
e traz bem para o que
elas falaram dessa
questão de trabalhar
a cidadania, não só a
questão sociopolítica
da criança, não só as
crianças, mas a escola
como um todo"
q...)Na minha educação
que tive a gente não
tinha muito espaço
para realmente falar o
que acha, para debater
e ter voz dentro da
escola. A gente só
ouvia, só recebia
informações, a gente
não tinha muito espaço
para falar realmente,
enfim, nada"




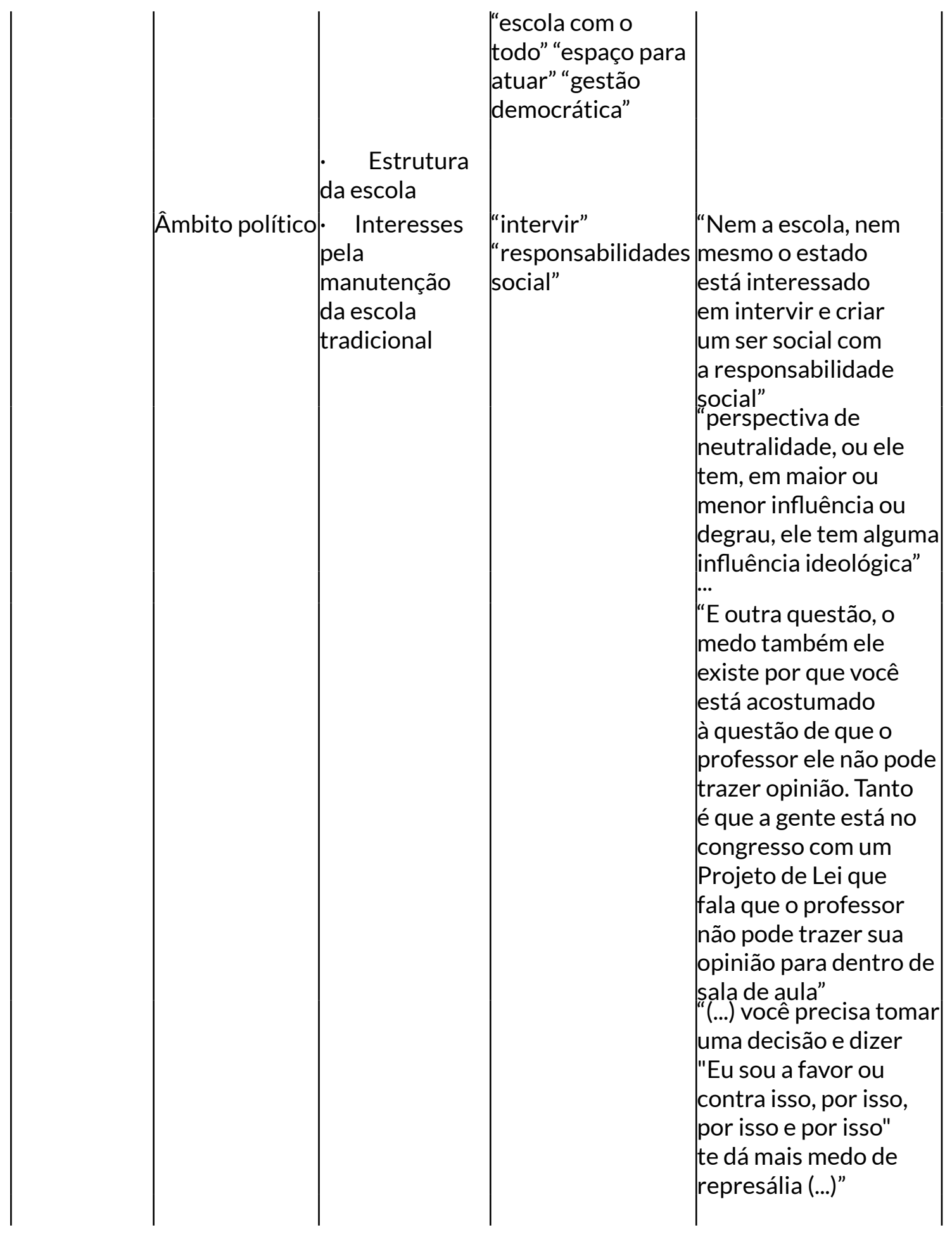




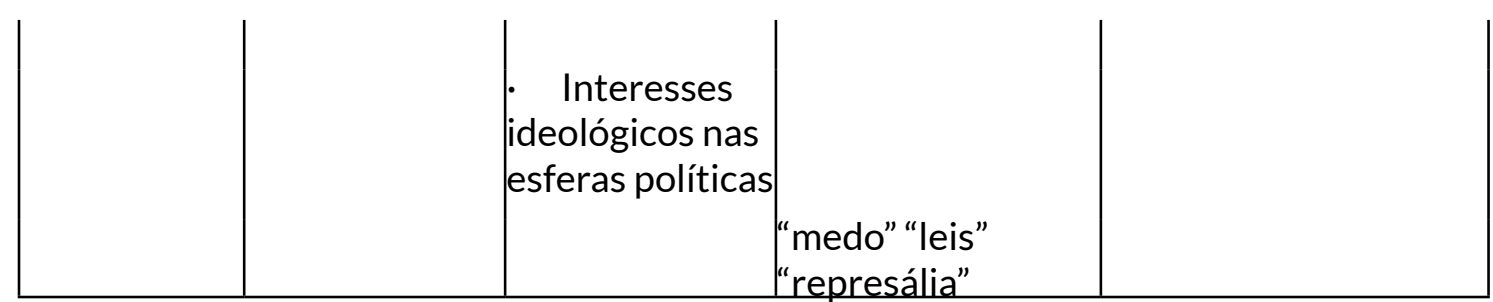

O segundo tema (Tabela 2), associado à Superação dos problemas e a tomada de consciência faz parte de um conjunto de falas que procuram compreender o papel do professor como ator da mudança. É interessante observar que para os investigados o professor e sua necessidade de compreender que o conhecimento não é o saber único e correto, pode ser um desses aspectos de superação para a inserção de controvérsias sócio-científicas nas salas de aulas. O processo formativo indica uma reflexão desses sujeitos acerca dos espaços universitários como fundamentais para a mudança de postura. Nesse sentido, os futuros professores ainda apontam que a necessidade de adquirir uma postura mais ativa pode ser instrumento fundamental para que essas questões ditas atuais sejam inseridas nas salas de aulas.

Na questão que se refere à tomada de consciência, a preocupação do papel do professor como o ator do desvelamento das relações sociais aparece em alguns momentos. Isto, pois os discursos se direcionam na tentativa de enfrentamento dos debates mais pessimistas que focam nas dificuldades ou falta de formação para atuarem nos contextos de inovação na escola. Em geral, algumas falas indicam a necessidade de superação desses pensamentos através de uma postura de reconhecimento da responsabilidade do docente em atuar como agente da transformação social (Freire, 2005). Outra categoria que foi mencionada no contexto de mudanças foi o da tecnologia. Para os futuro professores, ela pode ser um instrumento importante de interação entre diferentes mundos e de atualização da escola, enquanto os futuros professores apontam que a necessidade de interagir com o mundo externo à sala de aula é fator determinante para a inserção das questões sócio-científicas nas escolas. Ainda, retomam a necessidade de compreender que os alunos são parte de uma geração "digitalizada" em que a lógica: livro, caderno e lousa já não possuem sentido.

Contudo, chamam a atenção que, para tanto, o uso de tecnologias em sala de aula, não significa apenas inserir os produtos tecnológicos, mas articular esses materiais com a reflexão e a correlação com os conhecimentos que 
dela podem emergir. Portanto, não significa a defesa pelo seu uso, mas o reconhecimento de que para inserir controvérsias sócio-científicas é necessário que o professor compreenda que a tecnologia não é somente um aparato a ser utilizado, mas instrumento importante de reflexão e interação entre agentes sociais.

Cabe apontar nesse tema que o papel social e os reconhecimentos das interações sociais provindas da tecnologia são parte de um entendimento pelos futuros professores de suas responsabilidades diante dos problemas levantados. 
Tabela 2: Matriz de análise da superação e tomada de consciência

\begin{tabular}{|c|c|c|c|c|}
\hline Tema & Categorias & Subcategorias & $\begin{array}{l}\text { Indicadores/Unidades } \\
\text { de Registro }\end{array}$ & Unidades do Texto \\
\hline $\begin{array}{l}\text { Superação dos } \\
\text { problemas e } \\
\text { a tomada de } \\
\text { consciência }\end{array}$ & $\begin{array}{l}\text { Postura do } \\
\text { professor }\end{array}$ & $\begin{array}{l}\text { Conhecimento } \\
\text { Processo formativo }\end{array}$ & $\begin{array}{l}\text { detentor" "facilitador" } \\
\text { "preparar-se" } \\
\text { "mudança" }\end{array}$ & $\begin{array}{l}\text { "Assim, para mim ninguém tá } \\
\text { preparado para isso e se você } \\
\text { achar que é o único detentor do } \\
\text { conhecimento. Mas a partir do } \\
\text { momento que você é o facilitador } \\
\text { ali para o conhecimento deles" } \\
\text { "o papel de um professor é } \\
\text { exatamente isso, conseguir fazer } \\
\text { um equilíbrio entre aquilo que } \\
\text { ele sabe, aprender com o aluno e } \\
\text { ele chegar a uma coisa que tenha } \\
\text { significado para os dois" } \\
\text {... } \\
\text { "a gente não está habituadxa com } \\
\text { isso, então, eu acho que nem a } \\
\text { gente está 100\% preparado, mas } \\
\text { se a gente sabe que tem essa } \\
\text { possibilidade eu acho que a gente } \\
\text { tem que se preparar para isso" } \\
\text { "a gente não gosta muito desse } \\
\text { modelo tão tradicional de você } \\
\text { estar fechado ali e ter que seguir } \\
\text { aquilo" } \\
\text { "a gente mudar um pouco, por que } \\
\text { se a gente só falar que tá difícil e } \\
\text { não encarar quem vai fazer isso. Eu } \\
\text { queria fazer parte dessa mudança" } \\
\text { "Qual é nosso papel enquanto } \\
\text { alunos da academia e futuros } \\
\text { pedagogos. O que a gente vai } \\
\text { fazer? A gente vai continuar } \\
\text { tentando descobrir quais as novas } \\
\text { tecnologias podem ajudar na } \\
\text { alfabetização sem se preocupar } \\
\text { com a política, educação é filosofia, } \\
\text { considerando que somos passivos, } \\
\text { e deixando que a econômica } \\
\text { avance e a gente achando que } \\
\text { estamos nos destacando no } \\
\text { cenário internacional" }\end{array}$ \\
\hline
\end{tabular}




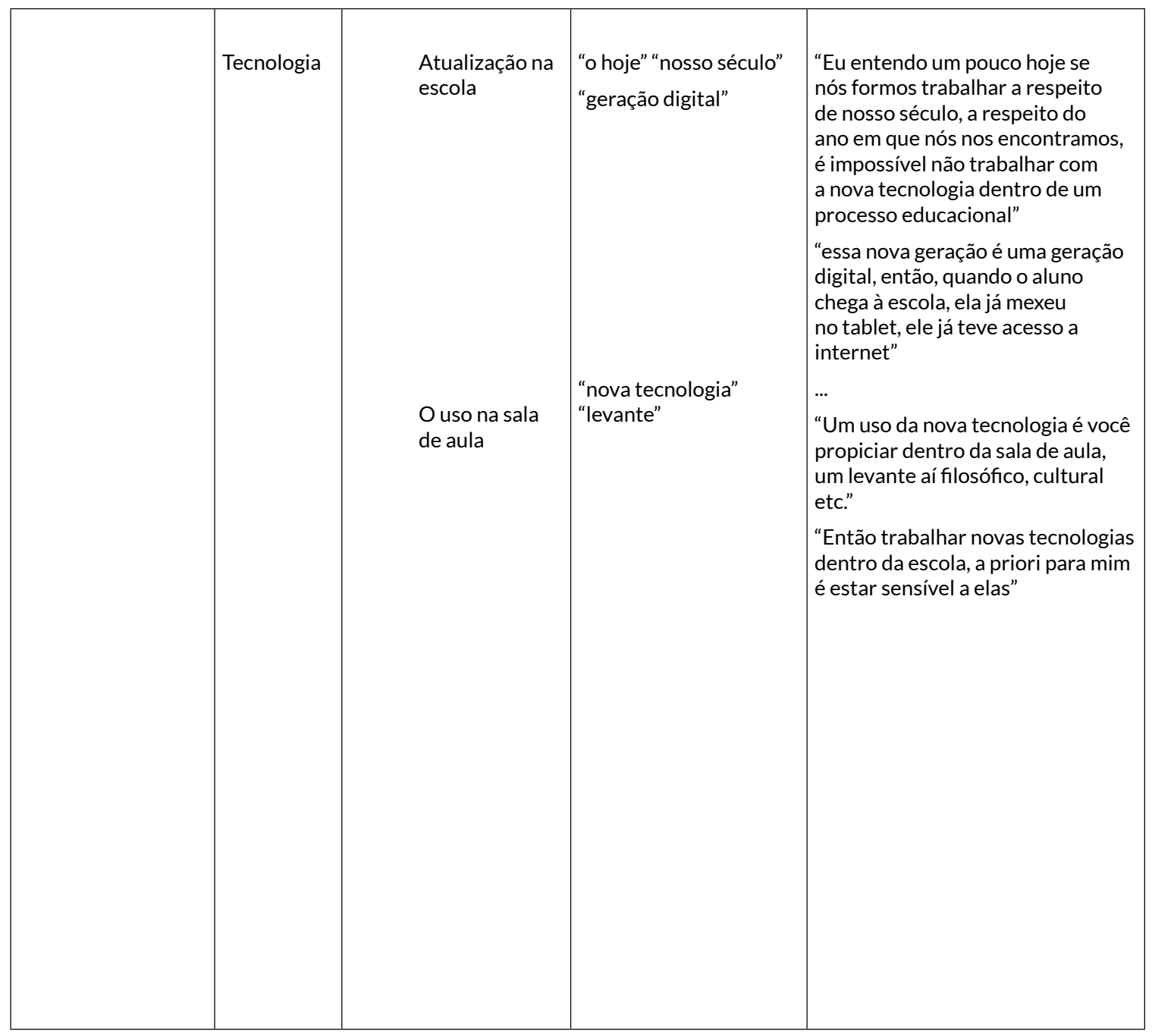

Os resultados aqui apresentados apontam para diferentes instâncias sociais que congregam objetivos e demandas para a escola. Em especial, chamam a atenção o modo como esses futuros professores reconhecem as controvérsias sócio-científicas como temáticas que podem ser instrumentos de embate entre eles e os grupos sociais que, em partes, possuem lugar nas decisões da escola.

Ao abordar temáticas que não podem ser tratadas unicamente por conhecimentos científicos, muito dos investigados apontam para as dúvidas sobre a validade dos embates com familiares e outros grupos sociais. No entanto, ao passo que os discursos são produzidos, coletivamente, percebe-se que esses futuros profissionais também apontam a necessidade de mudanças na escola e através da escola. As relações de 
poder, ainda que apresentadas de modo muito significativo como fator de empecilho pelos investigados, também, demonstra que seu reconhecimento pode ser o primeiro passo para a superação dos oprimidos/dominados nesse processo.

\section{Considerações Finais}

Com o objetivo de compreender como as relações de poder estão influenciando as decisões de futuros professores abordarem controvérsias sócio-científicas em suas aulas de ciências, o trabalho trouxe discursos e entendimentos sobre os desafios percebidos pelos investigados. Tal situação deve-se em grande parte pelo viés reflexivo e crítico que foi estabelecido na escolha dos textos, possibilitando espaço para debates que ultrapassem a esfera da prática para a reflexão dos problemas mais abrangentes, em muitos casos, particularizados pelo contexto social, cultural e político brasileiro. Essa condição de criticidade evocou uma análise mais profunda da ação no mundo, reconhecendo-o como um instrumento importante para as mudanças sociais e das desigualdades que estão associadas a tais transformações.

Assim, a teoria bourdieusiana auxiliou na compreensão de que em muitos casos, as dificuldades encontradas por futuros professores em abordar controvérsias científicas não se dão unicamente na esfera dos problemas conceituais ou nas posições de fragilidade encontradas em situações de incerteza em sala de aula. Fatores externos parecem dar indícios dos desafios que esses futuros docentes consideram encontrar ao abordar questões que antemão poderiam ser reconhecidas como problemas da esfera particular/familiar. Em específico, como casos em que as limitações se apresentam nas culturas tradicionais dos grupos que participam, de certo modo, indiretamente, do currículo nas escolas.

Pierre Bourdieu (1964) apontava o papel das culturas, que pode ser uma propriedade familiar, como um dos fatores de manutenção das classes dominantes. Nesse contexto, a mudança de um pensamento baseado na historicidade de um grupo pode se tornar algo ameaçador para esses agentes e suas posições sociais. Nesse sentido, é interessante pensar que a luta estabelecida na relação de poder entre família e a escola pode representar um fator determinante para as limitações de inserir controvérsias em sala de aula.

Isto, pois se a proposta de trabalhar com a transformação do mundo é promover a postura reflexiva e crítica dos estudantes, não há dúvidas que os grupos dominantes utilizarão de diferentes artimanhas para impedir o movimento de reflexão e questionamento na escola. Por tal motivo, para os futuros professores investigados o reconhecimento das diferentes relações de poder estabelecidas no seio escolar e social mais amplo acabam se apresentando como um fator crucial para as posturas 
de embaraço desses profissionais (em formação) diante do desafio de trabalhar tais temáticas.

Em função da participação e do controle social do trabalho docente, parece que os futuros professores se veem em situações de vigilância das suas ações. Esse debate acaba por trazer considerações que ainda merecem ser mais aprofundadas, mas indica uma percepção de que o mundo macrossocial não pode ser tratado de modo estanque aos contextos das interações em sala de aula. Para os investigados, cujo discurso requer pensar nas posições que os mesmo ocupam na estrutura social, essa dimensão é ainda mais forte. A desvalorização da prática docente acaba por conduzir a tomada de consciência de que o ato de educar se transforma em algo desafiante ao mesmo tempo em que se estabelece como ação vigiada.

Cabe pensar até que ponto uma sociedade dita democrática, mascarada pelas políticas e discursos ideológicos não estão conduzindo à propagação dos discursos de ódio, ataque as minorias ou a supervalorização da defesa pela tradição. O questionamento torna-se parte de uma visão de que a sociedade caminha para a desmoralização dos valores da família, conduzindo ao retrocesso das conquistas almejadas por alguns cientistas para a igualdade social.

Para Hirschman (1991) o levante do pensamento "reacionário" se dá no convencimento de que o bem leva ao efeito colateral. Em sua tese da perversidade o autor nos questiona:

A característica básica da tese da perversidade, porém, não muda: o homem está fadado ao ridículo (...) pois, ao dedicar-se à melhoria radical do mundo, extravia-se radicalmente. Que melhor maneira de mostrá-lo como meio tolo e meio criminoso senão provando que está realizando exatamente o contrário do que proclama como seu objetivo? Que argumento é melhor, além disso, contra uma política que se abomina mas cuja meta anunciada não se deseja atacar diretamente?

Em última instância, o desafio está dado, como conduzir a transformação a partir do saber científico, sem entrar na lógica de que o desejo de sucesso já nasce perdido? 0 próprio autor nos dá a resposta quando aponta que as ações humanas podem surtir o efeito contrário, ou seja, o mal também pode vir para o bem, nesse caso, a hora de promover a reflexão e a tomada de consciência se engrandece nos momentos obscuros. 


\section{Referências}

Bencze, L., \& Carter, L. (2011). Globalizing students acting for the common good. Journal of Research in Science Teaching, 48(6), 648-669.

Barbier, R. (2002). A pesquisa-ação. Brasília: Plano.

Bardin, L. (2009). Análise de Conteúdo. Lisboa: Edições 70.

Bourdieu, P. (1980). O senso prático. Rio de Janeiro: Vozes.

Bourdieu, P.. (1996). Sobre a televisão. Rio de Janeiro: Zahar.

Bourdieu, P., \& Passeron, J.-C. (1964). Os herdeiros: os estudantes e a cultura. Florianopólis: UFSC.

Burawoy, M. (2010). O marxismo encontra Bourdieu. Campinas: Unicamp.

Carvalho, L. M., \& Carvalho, W. L. (2012). Formação de professores e questões sóciocientíficas no ensino de ciências. São Paulo: Escrituras.

Catani, A. M. (2013). Origem e destino: pensando a sociologia reflexiva de Bourdieu. Campinas: Mercados das Letras.

Engström, S., \& Carlhed, C. (2014). Different habitus - different strategies in teaching physics? Cultural Studies of Science Education, online, pp. 1-30.

Franco, M. A. (2012). Pesquisa-ação e prática docente: articulações possíveis. In: S. C. Pimenta, \& M. A. Franco (Eds.). Pesquisa em educação: possibilidades investigativas/ formativas da pesquisa-ação (Vol. I, pp. 103-138). São Paulo: Loyola.

Franco, M. A., \& Lisita, V. M. (2012). Pesquisa-ação: limites e possibilidades na formação docente. In: S. G. Pimenta, \& M. A. Franco (Eds.) Pesquisa em educação: possibilidade investigativas/formativas da pesquisa-ação (Vol. II, pp. 41-70). São Paulo: Loyola.

Freire, P. (2005). Pedagogia do oprimido. São Paulo: Paz e Terra.

Freire, P. (2013a). Pedagogia da autonomia. São Paulo: Paz e Terra

Freire, P. (2013b). Educação como prática da liberdade. São Paulo: Paz e Terra.

Freire, P. (1975ab). Extensão ou comunicação? Rio de Janeiro: Paz e Terra.

Linhares, E.; \& Reis, P. (2014). La promotion del'activismechez les futurs enseignants partant de la discussion de questions socialement vives. Revue Francophone du développement durable, 4, 80-93. 
Pozo, J.I.; \& Crespo, M.A.G. (2009). Por que os alunos não aprendem a ciência que Ihes é ensinada? In: J.I. Pozo; \& Crespo, M.A.G. (Ed.) A aprendizagem e o ensino de ciências (Vol. 1, Cap. 1, pp. 14-28). Porto Alegre: Artmed.

Tilly, C. (2006). O acesso desigual ao conhecimento científico. Tempo social, 18(2), 47-63.

Levinson, R. (2006). Towards a Theoretical Framework for Teaching Controversial Socio-scientific Issues. International Journal of Science Education, 28(10), 12011224.

Reis, P. (2014a). Acción Socio-Politica sobre Cuestiones Socio-Científicas: Reconstruyendo La Formácion Docente y el Currículo. Uni/Pluriversidade, 14(2), 16-26.

Reis, P. (2014b). Promoting Student's Collective Socio-scientific Activism: Teachers' Perspectives. In: L. Bencze, \& S. Alsop (Ed.) Activism Science and Technology Education (Vol. 1, Cap. 3, pp. 547-574). New York: Cultural Studies of Science Educacion.

Tripp, D. (2005). Pesquisa-ação: uma introdução metodológica. Educação e Pesquisa, 31(3), pp. 443-466.

Vittoria, P. (2011). Narrando Paulo Freire: por uma pedagogia do diálogo. Rio de Janeiro: UFRJ.

Wacquant, L. (2005). O mistério do ministério: Pierre Bourdieu e a política democrática. Rio de Janeiro: Revan.

Graciella Watanabe é professora do Centro de Ciências Naturais e Humanas da Universidade Federal do ABC. Doutora e mestre em Ensino de Ciências na Modalidade Física pela Universidade de São Paulo e mestre em Educação pela Universidade de Lisboa. Tem se interessado pelos estudos em desigualdade educacional e, atualmente, é coordenadora do grupo de pesquisa DECiDe - Desigualdade Educacional, Ciência e Democracia.

Pedro Guilherme Rocha dos Reis é professor associado e diretor do Instituto de Educação da Universidade de Lisboa. Coordenados do Programa de Doutorado em Didática das Ciências. É biólogo e doutor em Didática das Ciências na Faculdade de Ciências da Universidade de Lisboa.. 